\title{
Comparative immunogenicity of preparations of yeast-derived dengue oral vaccine candidate
}

\author{
Jyotiranjan Ball, Nguyen Ngoc Luong ${ }^{2}$, Jisang Park ${ }^{1}$, Ki-Duk Song ${ }^{3}$, Yong-Suk Jang ${ }^{1}$ and Dae-Hyuk Kim ${ }^{\text {* }}$
}

\begin{abstract}
Background: Dengue is listed as a neglected tropical disease by the Center for Disease Control and Preservation, as there are insufficient integrated surveillance strategies, no effective treatment, and limited licensed vaccines. Consisting of four genetically distinct serotypes, dengue virus (DENV) causes serious life-threatening infections due to its complexity. Antibody-dependent enhancement by pre-existing cross-reactive as well as homotypic antibodies further worsens the clinical symptoms of dengue. Thus, a vaccine conferring simultaneous and durable immunity to each of the four DENV serotypes is essential to restrict its escalation. In deeply affected resource-limited countries, oral vaccination using food-grade organisms is considered to be a beneficial approach in terms of costs, patient comfort, and simple logistics for mass immunization. The current study used a mouse model to explore the immunogenicity of an oral dengue vaccine candidate prepared using whole recombinant yeast cells (WC) and cell-free extracts (CFE) from cells expressing recombinant Escherichia coli heat-labile toxin protein B-subunit (LTB) fused to the consensus dengue envelope domain III (sCEDIII). Mice were treated orally with recombinant WC and CFE vaccines in 2-week intervals for 4 weeks and changes in systemic and mucosal immune responses were monitored.
\end{abstract}

Results: Both WC and CFE dosage applications of LTB-sCEDIII stimulated a systemic humoral immune response in the form of dengue-specific serum IgG as well as mucosal immune response in the form of secretory slgA. Antigenspecific B cell responses in isolated lymphoid cells from the spleen and Peyer's patches further indicated an elevated mucosal immune response. Cellular immune response estimated through lymphocyte proliferation assay indicated higher levels in CFE than WC dosage. Furthermore, sera obtained after both oral administrations successfully neutralized DENV-1, whereas CFE formulation only neutralized DENV-2 serotype, two representative serotypes which cause severe dengue infection. Sera from mice that were fed CFE preparations demonstrated markedly higher neutralizing titers compared to those from WC-fed mice. However, WC feeding elicited strong immune responses, which were similar to the levels induced by CFE feeding after intraperitoneal booster with purified scEDIII antigen.

Conclusions: CFE preparations of LTB-SCEDIII produced strong immunogenicity with low processing requirements, signifying that this fusion protein shows promise as a potent oral vaccine candidate against dengue viral infection.

Keywords: Dengue, Oral vaccine, scEDIII, Saccharomyces cerevisiae, Neutralization, Mucosal immunity

\footnotetext{
*Correspondence: dhkim@jbnu.ac.kr

1 Department of Molecular Biology, Department of Bioactive Material

Sciences, Institute for Molecular Biology and Genetics, Chonbuk National

University, Jeonju, Jeollabuk-do 54896, Republic of Korea

Full list of author information is available at the end of the article
} 


\section{Background}

Dengue, a dreadful and rapidly spreading arthropodborne viral disease, affects an estimated 50-400 million people annually $[1,2]$. Currently, 2.5 billion people that constitute $\sim 40 \%$ of the world's population are at risk of dengue transmission, as it is endemic in at least 100 countries in Asia, the Pacific regions, the Americas, Africa, and the Caribbean. Although the first licensed dengue vaccine CYD-TDV [3] has been recently approved, more potent and effective vaccine developments are still required.

Dengue viruses (DENVs), are positive-stranded RNA viruses belonging to the family Flaviviridae. There are four closely related, but antigenically distinct, serotypes (DENV-1, -2, -3, and -4) that can be transmitted to humans through mosquitoes of the genus Aedes. Major implications of dengue such as, disease consequences, vaccine induced protection and epidemic immensity depends upon both antigenic and genetic differences among the DENV types [4]. Antibody-dependent enhancement of infection has been proposed as the primary mechanism of dengue immunopathogenesis [5]. Infection by one serotype confers lasting protection against re-infection by the same serotype, however, only transient protection or even detrimental results can occur following the secondary infection [6] by one of the three heterologous serotypes. These findings prompted us to consider a synthetic consensus target sequence from four serotypes to be used as a vaccine candidate.

Dengue infections are categorized as causing asymptomatic fever, dengue fever, and dengue hemorrhagic fever (DHF). DHF can be further classified into four severity grades, with grades III and IV causing dengue shock syndrome with potentially fatal outcomes in the absence of medical care [7, 8]. Despite these differences, each serotype causes nearly identical syndromes in humans and circulates in the same ecological niche. Thus, the ideal dengue vaccine should induce a life-long balanced and lasting immunity against all four DENV serotypes, be free of important reactogenicities, and be affordable.

The DENV envelope (E) protein interacts with several receptors for DENV entry and attachment $[9,10]$, and is the major protein eliciting a serotype-specific antibody response in the infected host. domain III of the E protein (EDIII) has been implicated in host receptor recognition. EDIII consists of multiple potent and type-specific neutralizing epitopes $[11,12]$ and acts as an effective antigen to elicit neutralizing antibodies in experimental animal models. This EDIII protein, a polypeptide sequence of $\sim 100$ amino acids, is an attractive target for the development of a recombinant vaccine [13]. A recent study that developed a consensus EDIII (cEDIII) immunogen by aligning sequences from different isolates of the four serotypes of dengue virus indicated that cEDIII elicits cross-neutralizing antibodies to block DENV1, DENV2, DENV3, and DENV4 infections simultaneously [14]. An engineered heterologous lipoprotein generated by fusing the consensus EDIII protein with lipid signal peptides (LcED III) showed promise in eliciting cellular and humoral immune responses as well as neutralizing antibodies against all four serotypes [15]. In addition, yeastexpressed scEDIII induced balanced immune responses against all four serotypes upon subcutaneous immunization in mice using purified protein emulsified in complete Freund's adjuvant (CFA) into mice [16].

The concept of oral vaccines has attracted a great deal of attention as they enable a higher capacity for mass immunizations during pandemics at relatively low cost. In addition, they help avoid the risks commonly associated with conventional vaccines, and they confer enhanced immune responses mucosally [17] and systemically. In general, oral vaccines cause less stress and associated immune-suppression for the recipient [17]. Therefore, oral delivery is considered to be an ideal and easy route to introduce foreign antigens. The local antigen presentation in the mucosal tissue is essential for effective tolerance and initiation of active immune responses. Recently, several molecules that could be used to target vaccine antigens to mucosal and systemic compartments have been identified. M cell-specific targeting of the tetravalent dengue antigen (Tet-EDIII) via the Co1 ligand achieved successful targeting to the antigen presenting cells (APCs) of the mucosal immune system [18]. In addition, the B subunit of cholera toxin (CTB) and Escherichia coli heat-labile enterotoxin (LTB) are highly efficient carrier molecules for chemically- or genetically-conjugated antigens for eliciting mucosal and systemic antibody responses [19] and mucosal tolerance for prophylactic vaccines against autoimmune diseases $[20,21]$. LTB was used in this study not only for its role as an effective adjuvant and carrier of proteins and epitopes, but also for targeting and eliciting the immune response due to the fact that LTB binds with high affinity to its cell surface receptor ganglioside GM1. Ganglioside GM1 binding results in enhanced targeting and access to major histocompatibility complex (MHC) compartments [22, 23], increased activation of APCs and T cells [24], and enhanced stability of the conjugated antigens.

Saccharomyces cerevisiae is generally recognized as safe (GRAS). Therefore, it is frequently employed in oral vaccine systems due to the advantage of it being a simple eukaryotic system with high expression capability, ease of scale-up, genetic manipulation, and culturing with the inherent advantage of eukaryotic post-translational modifications and secretion. Moreover, the cells are suitable to be taken up by APCs $[25,26]$. The whole recombinant 
yeast-based vaccine approach integrating efficient antigen delivery with dendritic cell activation without the need for accessory adjuvant components suggests its potential efficiency as an oral vaccination candidate [27]. Furthermore, it has great potential as a system for provoking antigen-specific antibody responses [28]. The use of recombinant $S$. cerevisiae as an oral vaccine and drug delivery system is enhanced by its ability to be absorbed by $\mathrm{M}$ cells in the Peyer's patches (PP) of the gut [29]. Oral administration of freeze-dried S. cerevisiae cells expressing the porcine circovirus type 2 (PCV2b) Cap protein on their surface induces protection against subsequent PCV2b challenge; moreover, its properties allow for easier vaccine storage and transport, thus enhancing its attractiveness as a vaccine [30]. Moreover, large amounts of recombinant yeast-producing protein antigens can be easily obtained at low cost. Therefore, strategies using whole recombinant yeast to deliver protein antigens may have the potential for successful antigen delivery and may lead to the induction of cell-mediated immunity directed against a variety of infectious agents.

Taking into consideration the immunogenic efficacy of scEDIII, the efficient mucosal targeting and elicitation of immune responses by LTB, and the fact that S. cerevisiae provides an effective vaccine delivery system, we performed a comparative analysis to evaluate the efficacies of dengue virus oral vaccines using WC and CFE preparations of S. cerevisiae-expressed E. coli LTB-conjugated dengue scEDIII as an oral vaccine candidate in a BALB/c mouse model.

\section{Methods}

\section{Animal housing and ethics statement}

Five-week-old female BALB/c mice procured from the Charles River Laboratories through Orient Bio, Inc. (Sungnam, Korea) and maintained under general specific pathogen-free conditions were used for immunization purposes. Six mice were housed in each filtertop microisolator cage in a temperature- and humidity-controlled room. Mice were acclimated for approximately 1 week prior to the initiation of the oral feeding experiment. Experimental procedures involving laboratory animals strictly adhered to the guidelines set out by the Institutional Animal Care and Use Committee of the Chonbuk National University (Approval Number: CBU 2015-0004).

\section{Reagents}

An anti-dengue virus primary monoclonal antibody $(\mathrm{mAb})$ was procured from LifeSpan BioSciences, Inc., Seattle, WA, USA, and anti-LTB was from Immunology Consultants Laboratory Inc., Portland, OR, USA.

\section{Construction of an LTB-scEDIII expression vector for expression in S. cerevisiae}

LTB and S. cerevisiae codon-optimized scEDIII genes [16] were amplified from pYEGLTB [31] and pUC19 harboring scEDIII, respectively. The two resulting polymerase chain reaction (PCR) amplicons were fused by overlap extension PCR using the primers cEIII-LTB OF (5'-GTATGGAAAACGGACCAGGTCCTAAAGGAA TGTC-3') and cEIII-LTB OR (5'-GACATTCCTTTA GGACCTGGTCCGTTTTCCATAC- $3^{\prime}$ ) and DNA polymerase from Takara Bio Inc. In addition, BamHI and SalI restriction sites were included at the $5^{\prime}$ and $3^{\prime}$ ends, respectively, to facilitate subsequent cloning using the primers Con-F (5'-CGGGATCCCGATGAAAGGAAT GTCTTACGCA-3') and Con-R (5'-GACGTCGACGCC TATGAGGAACCCTTTTTAAACCA-3'). The fusion construct was cloned into the yeast episomal shuttle vector, pYEGPD-TER [31] to construct pYEG-LTB-scEDIII with glyceraldehyde-3-phosphate dehydrogenase (GPD) as the promoter and galactose-1-phosphate uridyl transferase (GAL7) as the terminator (Fig. 1a). The resulting clones were confirmed through restriction enzyme digestion and DNA sequencing. The expression host S. cerevi-

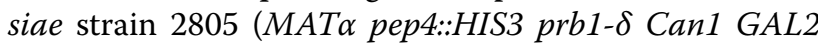
his3 ura3-52) [32] was transformed by pYEG-LTB-scEDIII using the lithium acetate method [33]. Empty vector pYEGPD-TER-transformed yeast served as the mock immunization-negative control.

\section{Northern blot analysis for selecting expression-efficient clones}

Total yeast RNAs extracted from the selected clones as described previously [16] were separated on a $1.2 \%$ formaldehyde-agarose gel, transferred to an Amersham Hybond $^{\mathrm{TM}}$ membrane, and hybridized with an $\alpha-\left[{ }^{32} \mathrm{P}\right]$ labeled probe generated using a random labeling kit (Amersham Pharmacia Biotech, Piscataway, NJ, USA). The northern blot was developed to visualize the expression pattern of LTB-scEDIII. Expression of the S. cerevisiae GPD housekeeping gene served as a reference.

\section{Culture conditions and target protein expression analysis}

The S. cerevisiae transformants containing pYEG-LTBscEDIII were maintained in uracil-deficient $\left(\right.$ ura $^{-}$) selective medium, $(0.67 \%$ yeast nitrogen base without amino acids, $0.003 \%$ each of adenine and tryptophan, $0.5 \%$ casamino acids, and $2 \%$ dextrose). Initial seeding was prepared by inoculating $5 \mathrm{~mL}$ of ura ${ }^{-}$medium with a recombinant $S$. cerevisiae colony in a $15-\mathrm{mL}$ Falcon tube, followed by culturing for $48 \mathrm{~h}$ at $30{ }^{\circ} \mathrm{C}$ with vigorous shaking $(200 \mathrm{rpm})$. The secondary seeding was prepared by inoculating $5 \mathrm{~mL}$ of YEPD (1\% yeast extract, 


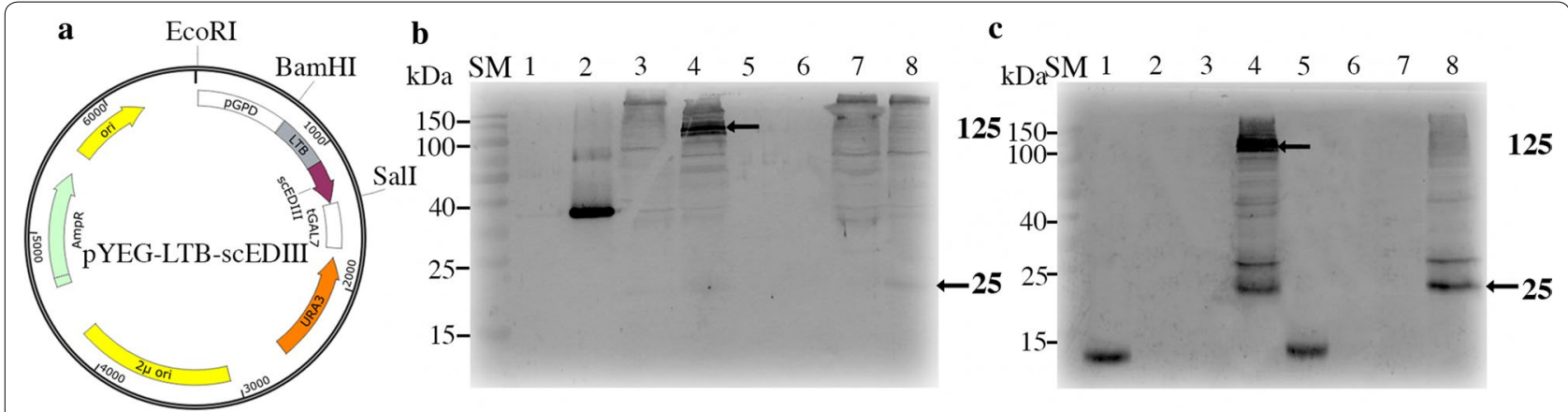

Fig. 1 Expression vector construct and expression analysis. a Schematic illustration of the expression plasmid pYEG-LTB-scEDIII. Western blot analysis of recombinant Escherichia coli heat-labile toxin protein B-subunit (LTB) fused to the consensus dengue envelope domain III (scEDIII) in cell-free extracts (CFEs) using $\mathbf{b}$ anti-LTB IgG and $\mathbf{c}$ anti-dengue IgG antibodies under non-denaturing (lanes 1-4) and denaturing conditions (lanes 5-8). Lanes 1 and 5 contain $1 \mu \mathrm{g}$ of total soluble protein (TSP) extracted from E. coli-expressed scEDIII [14] and lanes 2 and 6 contain $1 \mu \mathrm{g}$ of TSP from S. cerevisiae-expressed LTB [32] as positive controls. Lanes 3 and 7 contain $40 \mu \mathrm{g}$ of TSP extracted from mock-transformed yeast as negative controls. Lanes 4 and 8 contain $40 \mu \mathrm{g}$ of TSP extracted from recombinant LTB-sCEDIII. SM represents protein size marker. Arrows indicate the recombinant LTB-scEDIII protein. The numbers in bold letters on the right indicate the estimated sizes in $\mathrm{kDa}$

$2 \%$ peptone and $2 \%$ dextrose) medium with $250 \mu \mathrm{L}$ of the primary seeding, followed by culturing for $16 \mathrm{~h}$ at $30{ }^{\circ} \mathrm{C}$ with continuous agitation $(200 \mathrm{rpm})$. Subsequently, $40 \mathrm{~mL}$ of YEPD medium was inoculated with this secondary seeding in a 300-mL Erlenmeyer flask, followed by culturing for 3 day under the same conditions. The cultures were harvested and washed twice with PBS. The fresh weights were recorded, and the samples were stored at $-80{ }^{\circ} \mathrm{C}$ for future use. The E. coli strains were maintained in Luria-Bertani (LB) broth with the appropriate antibiotics.

For target protein expression analysis, CFEs were prepared as described previously [16]. Protein concentration was determined by Bradford assay using the Bio-Rad Protein Assay Kit (Bio-Rad, Hercules, CA, USA). Sample aliquots of the CFEs were separated by SDS-polyacrylamide gel electrophoresis (SDS-PAGE), and transferred onto Hybond- $\mathrm{C}$ extra nitrocellulose filter membranes (Hybond, Amersham Pharmacia Biotech). Primary antidengue virus mAb (LifeSpan BioSciences Inc.) and antiLTB (Immunology Consultants Laboratory Inc.) that recognized scEDIII and LTB, respectively, were used to detect target proteins. After incubation with goat anti-mouse IgG alkaline phosphatase conjugate (SigmaAldrich, St. Louis, MO, USA), the blots were developed by BCIP/NBT in TMN buffer $(100 \mathrm{mM}$ Tris $\mathrm{pH}$ 9.5, $5 \mathrm{mM} \mathrm{MgCl}_{2}$, and $100 \mathrm{mM} \mathrm{NaCl}$ ). Purified protein extract from the BL21 $\mathrm{E}$. coli strain expressing scEDIII [16] was used as a positive control.

\section{Estimation of target protein concentration in CFE}

Based on our previous study [34], the amount of recombinant yeast fed to each mouse per dose was determined to be $1.6 \mathrm{~g}$ fresh weight of recombinant yeast. To ensure that the equivalent quantities of target protein were fed to all mice, we estimated the amount of target protein in the CFEs from the equivalent weight of cells used as recombinant whole cells. Briefly, CFEs were prepared from $1.6 \mathrm{~g}$ wet weight of recombinant yeast cells as described previously [35]. Total soluble protein (TSP) concentration was determined by Bradford assay using the Bio-Rad protein assay kit (Bio-Rad). TSP $(40 \mu \mathrm{g})$ was coated onto NUNC Maxisorp 96-well enzyme linked immunosorbent assay (ELISA) plates and probed using anti-dengue virus mAb (LifeSpan BioSciences Inc.) to estimate the amount of scEDIII. Total recombinant scEDIII in CFE was quantified based on a standard curve of known amounts of purified E. coli-expressed scEDIII [35].

\section{Preparation of oral doses and quantification of $S$. cerevisiae-expressed LTB-scEDIII}

Using the optimal dosage of target protein is necessary to successfully elicit comparable immune responses. According to our previous study, $1.6 \mathrm{~g}$ fresh weight of yeast cells was near the maximum dose for oral feeding in mice [34]. We prepared the samples to feed equivalent amounts of recombinant protein irrespective of $\mathrm{WC}$ and CFE. Briefly, $20 \mathrm{~g}$ fresh weight of recombinant yeast cells was harvested from $640 \mathrm{~mL}$ of culture and subsequently divided into two parts: one part was used as WC for oral feeding and the other part was used to prepare CFEs. CFEs from $1.6 \mathrm{~g}$ of recombinant yeast cells resulted in a total of $15.5 \mathrm{mg}$ of TSP. The total amount of LTB-scEDIII was estimated using quantitative ELISA. Based on a standard curve of known amounts of purified E. coli-expressed scEDIII, we found that $1.3 \%$ of TSP corresponded to scEDIII for a total amount of $\sim 200 \mu \mathrm{g}$ of recombinant scEDIII in a single dose. 


\section{Mice immunization and collection of blood and fecal samples}

Prior to oral administration, groups of mice were fasted overnight (water was provided ad libitum). Oral feeding with WC and CFE preparations was performed using a 1-mL syringe fitted with an oral feeding needle. The four groups consisting of six BALB/c mice were fed separately with, Mock WC, LTB-scEDIII WC, Mock CFE, or LTB-scEDIII CFE. Each BALB/C mouse in the WC group was administered $1.6 \mathrm{~g}$ fresh weight of cells, resuspended in a final volume of $2.4 \mathrm{~mL}$ of PBS, split equally, and orally gavaged four times per dose on every alternate week for 4 weeks as depicted in Fig. 2 with minimum distress. Simultaneously, each mouse in the CFE group was administered the amount of TSP estimated in CFE extracted from 1.6 fresh weight of recombinant yeast cells in a final volume of $2.4 \mathrm{~mL}$ of PBS, split equally and orally gavaged four times per dose. To investigate the memory response, an intraperitoneal injection of $20 \mu \mathrm{g}$ of alum-adsorbed purified E. coli-expressed scEDIII was administered to each immunized mouse 3 weeks after the last oral immunization. Blood and fecal pellets were collected periodically from each mouse at day (d)4, d11, d18, $\mathrm{d} 25$, and $\mathrm{d} 32$ after the last oral immunization (Fig. 2). Blood was collected through retro-orbital bleeding, maintained at room temperature for $1 \mathrm{~h}$ to clot, and kept overnight at $4{ }^{\circ} \mathrm{C}$ to facilitate clot retraction before serum was recovered for storage at $-20{ }^{\circ} \mathrm{C}$. Extracts from the collected fecal matter were prepared in PBS for ELISA analysis. To observe memory response, weeks after final immunization, intraperitoneal injection of a booster dose of $E$. coli expressed purified scEDIII antigen was given. Then, retro-orbital bleeding was performed after 3 days of injection.

\section{ELISA detection of anti-dengue antibodies}

Changes in humoral immune responses upon oral administration of recombinant WC and CFE were analyzed by estimating the antibodies induced through indirect ELISAs using NUNC Maxisorp 96-well ELISA plates coated with $100 \mathrm{ng} /$ well of $E$. coli-expressed recombinant scEDIII protein. The plates were washed three times with PBS + 0.05\% Tween 20 (PBST) and blocked with $1 \%$ BSA in PBS for $2 \mathrm{~h}$ at $37{ }^{\circ} \mathrm{C}$. Following the washes, twofold serial dilutions were performed after adding $100 \mu \mathrm{L} /$ well of sera from immunized mice (the starting dilution points were 1:25 for serum IgG and 1:2 for fecal $\operatorname{sigA}$ ), and the plates were incubated overnight at $4{ }^{\circ} \mathrm{C}$. Alkaline phosphatase (AP)-conjugated secondary antibodies (anti-mouse IgG or IgA; Sigma-Aldrich) diluted 1:5000 in PBS containing $0.5 \%$ BSA were added and incubated for $2 \mathrm{~h}$ at $37^{\circ} \mathrm{C}$ followed by a washing step. To detect the response, $100 \mu \mathrm{L} /$ well of phosphatase substrate (S0942, Sigma-Aldrich) was added and incubated for $15 \mathrm{~min}$ at room temperature. The reaction was stopped with $2 \mathrm{M}$ $\mathrm{H}_{2} \mathrm{SO}_{4}$ and the optical density was measured at $405 \mathrm{~nm}$ using a microplate reader (Multiskan ${ }^{\mathrm{TM}}$ GO Microplate Spectrophotometer, Thermo Scientific Inc., Waltham, MA, USA).

The functional pentameric conformation of yeast expressed LTB-scEDIII was validated for its ability to bind to the GM1-ganglioside receptor using the GM1 ELISA. NUNC Maxisorp 96-well ELISA plates were coated with $3 \mu \mathrm{g} / \mathrm{mL}$ of monosialoganglioside GM1 (G-7641, SigmaAldrich) and incubated at $4{ }^{\circ} \mathrm{C}$ overnight. The plates were washed three times with PBS $+0.05 \%$ Tween 20 (PBST) and blocked with $1 \%$ BSA in PBS for $2 \mathrm{~h}$ at $37^{\circ} \mathrm{C}$. Following the washes, the plates were further coated with twofold serial dilutions of $S$. cerevisiae-expressed LTB [38]

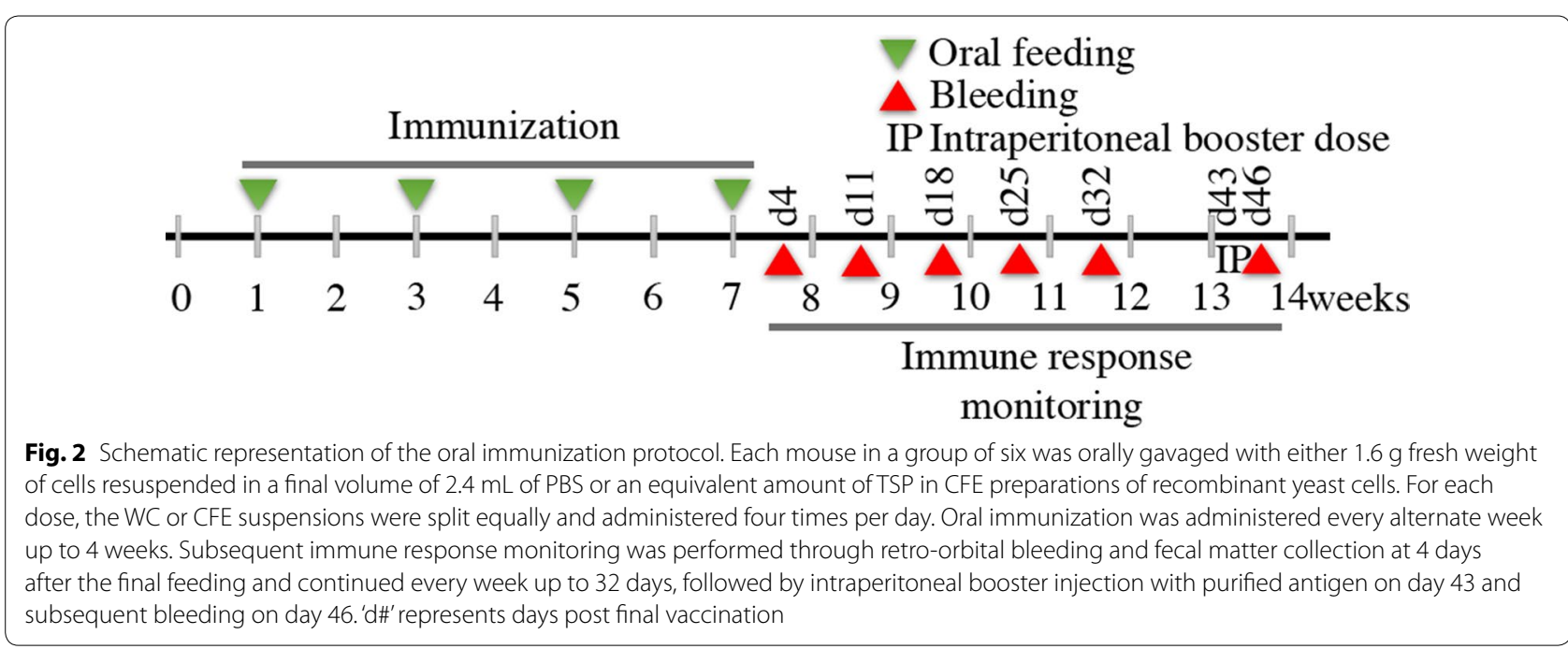


and LTB-scEDIII CFE and Mock CFE, and then incubated $2 \mathrm{~h}$ at $37^{\circ} \mathrm{C}$. Following the washes, GM1 binding was proved using primary antibody (rabbit anti-LTB) and alkaline phosphatase (AP)-conjugated secondary antibodies (anti-rabbit IgG; Sigma-Aldrich) diluted 1:5000 in PBS containing $0.5 \%$ BSA followed by the measurement of optical density at $405 \mathrm{~nm}$ using a microplate reader following similar steps as mentioned above.

\section{Lymphocyte proliferation assay}

A thymidine incorporation assay as described by Park et al. [36] was used to estimate antigen specific lymphocyte stimulation in isolated lymphocytes of immunized mice. Briefly, isolated lymphocytes $\left(5 \times 10^{5}\right)$ were treated with $2 \mu \mathrm{g}$ antigen and distributed into each well of a 96-well plate. When the cells in the PBS-treated negative control attained death phase, $0.5 \mathrm{mCi}$ of $\left[{ }^{3} \mathrm{H}\right]$-TdR (Amersham Life Science, Buckinghamshire, UK) was added to each well to pulse and test for proliferating cells. Stimulation indices (SI) were calculated by dividing the tritium incorporation (cpm), counted using a liquid scintillation counter (Perkin-Elmer, Waltham, MA, USA), in cells treated with antigen by the incorporation in control cells treated with PBS.

\section{Enzyme-linked immunosorbent spot (ELISPOT) assay}

ELISPOT assay were used as described previously [37, 38 ] to estimate the number of scEDIII-specific IgG or IgA secreting cells in the lymphocytes isolated from spleen, small intestinal lamina propria (LP), and PP of immunized mice. The PPs were carefully excised from the small intestines of mice, and further dissociated into single $\mathrm{T}$ cells by stirring with collagenase $\mathrm{D}(0.5 \mathrm{mg} / \mathrm{mL})$ and DNase I $(100 \mu \mathrm{g} / \mathrm{mL})$ for $60 \mathrm{~min}$ at $37^{\circ} \mathrm{C}$. LP cells were prepared by cutting small intestine tissue without PPs into small pieces and then digested with collagenase $\mathrm{D}(0.5 \mathrm{mg} / \mathrm{mL})$ and DNase I $(100 \mu \mathrm{g} / \mathrm{mL})$ for $60 \mathrm{~min}$ at $37^{\circ} \mathrm{C}$. MLN lymphocytes were similarly prepared by the digestion procedure described above.

\section{DENV neutralization assays}

A flow cytometry-based neutralization assay was conducted with U937 + DC-SIGN cells using a protocol similar to that described by Krauss et al. [39]. The DENVs used in this study were kindly provided by Dr. Truong (National Institute of Hygiene and Epidemiology of Vietnam, Hanoi, Vietnam) and propagated in a C6/36 cell line (American Type Culture Collection, Manassas, VA, USA). Briefly, the immune sera collected at $\mathrm{d} 32$ after last oral immunization, were serially diluted using five twofold dilutions and incubated with a total of $5 \times 10^{6} \mathrm{FACS}$ infectious units (FIUs) of DENV for $1 \mathrm{~h}$ at $37^{\circ} \mathrm{C}$ under $5 \% \mathrm{CO}_{2}$. The mixture was then added to the 96-well plate containing $5 \times 10^{4}$ U937 + DC-SIGN cells and incubated at $37{ }^{\circ} \mathrm{C}$ under $5 \% \mathrm{CO}_{2}$. At $2 \mathrm{~h}$ post-infection, the cells were washed twice with fresh infection medium and incubated at $37^{\circ} \mathrm{C}$ under $5 \% \mathrm{CO}_{2}$. At $24 \mathrm{~h}$ post-infection, the cells were washed, fixed, permeabilized, and stained for DENV E protein using $\mathrm{mAB} 2 \mathrm{H}_{2}$ conjugated to Alexa Fluor 488 (Millipore; Billerica, MA, USA); the percentages of infected cells were measured using flow cytometry. Sigmoidal neutralization curves were generated using GraphPad Prism Mac version 6.0e software. The fluorescence activated cell-based neutralization titer $\left(\mathrm{FNT}_{50}\right)$ of the immune serum was defined as the serum dilution resulting in a $50 \%$ reduction in the number of DENVinfected cells.

\section{Statistical analysis}

The statistical significance of the difference between the experimental parameters was determined by two-tailed Student's $t$ test and ANOVA, wherever indicated, using GraphPad Prism Mac version 6.0e. $p<0.05$ were considered to indicate significance.

\section{Results}

\section{Expression of LTB-scEDIII in S. cerevisiae}

The recombinant plasmid pYEG-LTB-scEDIII harboring the target gene scEDIII under the control of GPD promoter and GAL7 terminator was successfully constructed and transformed into S. cerevisiae 2805 strain as described in materials and methods. Eleven presumed recombinant plasmid (pYEG-LTB-scEDIII)-harboring transformants selected from ura $^{-}$selective medium were further scrutinized with colony PCR and E. coli back transformation to confirm the presence of the recombinant plasmid pYEG-LTB-scEDIII. Northern blot analysis of the selected transformants revealed the accumulation of the scEDIII transcript in all transformants (Additional file 1: Figure S1). Among these transformants, one (\#5 strain showing the highest transcript level in Additional file 1: Figure S1) was selected for subsequent experiments based on the high expression level of the LTB-scEDIII transcript relative to the internal control (GPD), as evidenced by the densitometric comparison of band intensities (Additional file 1: Table S1).

The selected $S$. cerevisiae transformant strain harboring the pYEG-LTB-scEDIII plasmid was cultured, and production of the target protein was examined using western blot analysis. The presence of LTB-scEDIII fusion protein was confirmed by the cross-reactivity of the protein preparation with anti-LTB anti-dengue antibodies. By probing through both anti LTB and anti scEDIII, it showed the presence of the LTB-scEDIII protein band at $\sim 125 \mathrm{kDa}$ under non-denaturing conditions and at approximately $25 \mathrm{kDa}$ under heat-denaturing conditions (Fig. 1b, c). 


\section{Functional pentameric conformation of S. cerevisiae expressed LTB-scEDIII}

The pentameric conformations of LTB is essential for GM1 ganglioside receptor binding which is vital for antigen uptake into mucosal system. Thus, we analyzed the oligomeric conformation of LTB-scEDIII by western blot analysis using anti-LTB and anti-dengue antibodies. Western blot analyses revealed the presence of the LTBscEDIII protein band at $\sim 125 \mathrm{kDa}$ under non-denaturing conditions and at approximately $25 \mathrm{kDa}$ under heat-denaturing conditions (Fig. 1b, c). These results suggested that the LTB-scEDIII fusion protein assembled into a pentameric form under native conditions, which is essential for binding the GM1 ganglioside receptor. This functional pentameric conformation was further validated for its ability to bind to the GM1-ganglioside receptor using the GM1 ELISA (Additional file 1: Figure S2). The results of the GM1 ELISA indicated that the LTB-scEDIII fusion protein exhibited a strong affinity to GM1 gangliosides, whereas the mock transformants showed no affinity to GM1 gangliosides. These results strongly suggest that the LTB-scEDIII fusion protein assembled into its oligomeric structure without hindrance from scEDIII. Furthermore, it maintained its functionality of receptor binding, which is required for target protein entry via ligand-specific binding activity of the pentameric LTB.

\section{Evaluation of the systemic humoral immune response elicited upon oral immunization with recombinant LTB-scEDIII in WCs and CFEs}

LTB is an effective mucosal adjuvant and $S$. cerevisiae cells have multiple adjuvant properties, making them an ideal combination to elicit both cellular and humoral immune responses. Thus, we explored the immunogenicity of yeast-expressed LTB-scEDIII through oral administration of two dosage forms: WCs (LTB-scEDIII WC) and CFEs (LTB-scEDIII CFE). Mice immunized with LTB-scEDIII WC and LTB-scEDIII CFE revealed significantly higher scEDIII-specific IgG antibody titers compared to Mock WC and Mock CFE obtained from mock transformants (Fig. 3). The immune responses showed prime-boost-dependent kinetics, with antibody titer sharply rising following the second boost. However, mice immunized with LTB-scEDIII WC showed lower levels of scEDIII-specific IgG compared with those immunized with LTB-scEDIII CFE. No scEDIII-specific IgG antibodies were detectable in the mice administered with Mock CFE and Mock WC.

\section{Evaluation of the mucosal immune response elicited upon oral immunization with recombinant LTB-scEDIII in WCs and CFEs}

The mucosal immune response evaluated by fecal sIgA antibody titers with ELISA showed that mice immunized with LTB-scEDIII CFE or LTB-scEDIII WC elicited scEDIII-specific fecal sIgA; however, mice immunized with LTB-scEDIII CFE demonstrated higher levels than those immunized with LTB-scEDIII WC (Fig. 4). These results suggest that orally administered LTB-scEDIII is targeted to the intestinal lymphoid tissues where it induces mucosal antibody responses.

To further confirm the scEDIII-specific mucosal immune responses, we performed ELISPOT assays on lymphocytes isolated from mucosal tissues such as spleen, LP, and PP from immunized mice. Briefly, 7 days after the last booster vaccination, two mice were

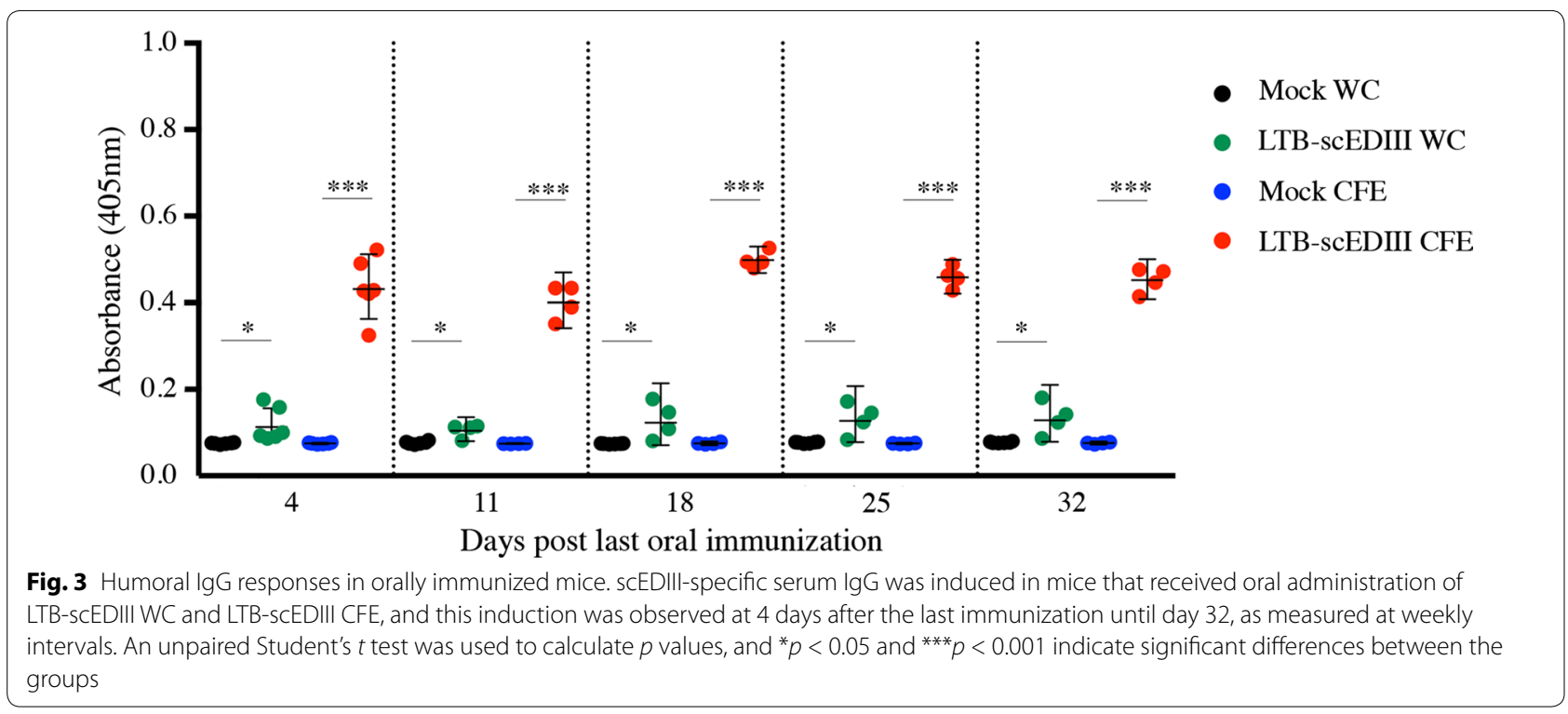




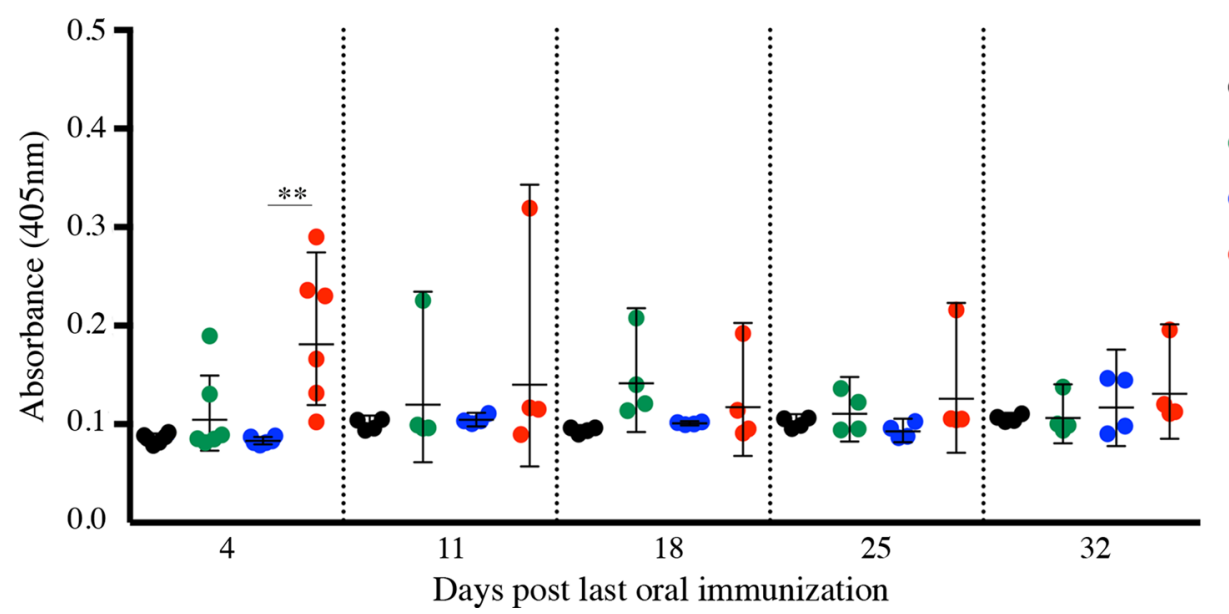

Fig. 4 Mucosal slgA responses upon oral immunization. scEDIII-specific fecal slgA was induced in mice immunized orally with recombinant LTB-sCEDIII WC and LTB-sCEDIII CFE at 4 days after the last immunization until day 32, observed at weekly intervals. An unpaired Student's $t$ test was used to calculate $p$-values, and ${ }^{*} p<0.05$ and ${ }^{* *} p<0.01$ indicate significant differences between the groups

sacrificed from each group, and their spleens, LP, and PP were retrieved. Lymphocytes were isolated from the tissues and probed for scEDIII-specific IgG- and IgAsecreting cells through ELISPOT assays. The number of scEDIII-specific antibody forming cells (AFCs) in the form of spot-forming cells (SFCs) in the spleen, LP, and PP lymphocytes differed considerably between LTBscEDIII-administered mice and their Mock-administered counterparts, irrespective of dosage type (Fig. 5). Furthermore, comparatively higher numbers of scEDIII-specific IgG AFCs in splenic lymphocytes and scEDIII-specific IgA AFCs in the PP and LP lymphocytes were observed in the LTB-scEDIII CFE than in the LTB-scEDIII WC mice. The mucosal cells from Mock-fed mice showed no scEDIII-specific IgG AFCs or IgA AFCs in mucosal cells. After booster stimulation with scEDIII purified antigen, lymphocytes were collected and analysed. Comparatively higher numbers of scEDIII-specific IgG AFCs in splenic lymphocytes were observed after administration of antigenic booster dose (Additional file 1: Figure S3). These results revealed that the enhanced mucosal immune responses were due to the oral administration of LTBscEDIII, suggesting that the enhanced levels of scEDIIIspecific serum IgG and fecal IgA were caused by the efficient targeting to the mucosal immune system due to the presence of LTB on the fusion protein.

\section{Elevation of cellular immune responses with LTB-scEDIII oral immunization}

Although oral immunization with recombinant LTB-scEDIII WC and CFE induced dengue ${ }_{1}$-specific serum IgG and mucosal sIgA production, cell-mediated immune responses also play a crucial role in protecting the host from invading pathogens. Therefore, we evaluated the proliferative response of isolated splenic lymphocytes primed with the scEDIII antigen in vitro to determine the systemic cellular immune response to LTB-scEDIII oral immunization. The SI of the lymphocytes from CFE immunized mice was significantly higher $(\mathrm{p}<0.05)$ than those of the WC and Mock. However, lymphocytes from WC immunized mice revealed similar proliferative activity with that of Mock immunized mice. These results suggested that LTB-scEDIII CFE oral immunization resulted in better cellular immune response than that of $\mathrm{WC}$ (Fig. 6).

\section{LTB-scEDIII induced EDIII-specific neutralizing antibodies}

A major goal in dengue vaccine development is to obtain sufficient neutralizing efficiency of the candidate vaccine against all serotypes of dengue virus. Following the preliminary analysis of the antibodies elicited by oral immunization with LTB-scEDIII, we next sought to determine whether these could prevent DENV from infecting susceptible cells. Thus, we employed a FACS-based virus neutralization assay against DENV1 and DENV2, which are the two representative serotypes responsible for severe dengue infection. The neutralization assay results revealed that sera from mice orally immunized with LTBscEDIII CFE or LTB-scEDIII WC neutralized DENV1, whereas LTB-scEDIII CFE rather than LTB-scEDIII WC could only neutralize DENV2 (Fig. 7). However, the neutralization titers of sera from mice immunized with LTBscEDIII CFE were comparatively higher than those of sera from mice immunized with LTB-scEDIII WC. The LTB-scEDIII CFE-derived antibodies successfully neutralized DENV1 with $\mathrm{FNT}_{50}$ titers $>22$ and DENV2 with 


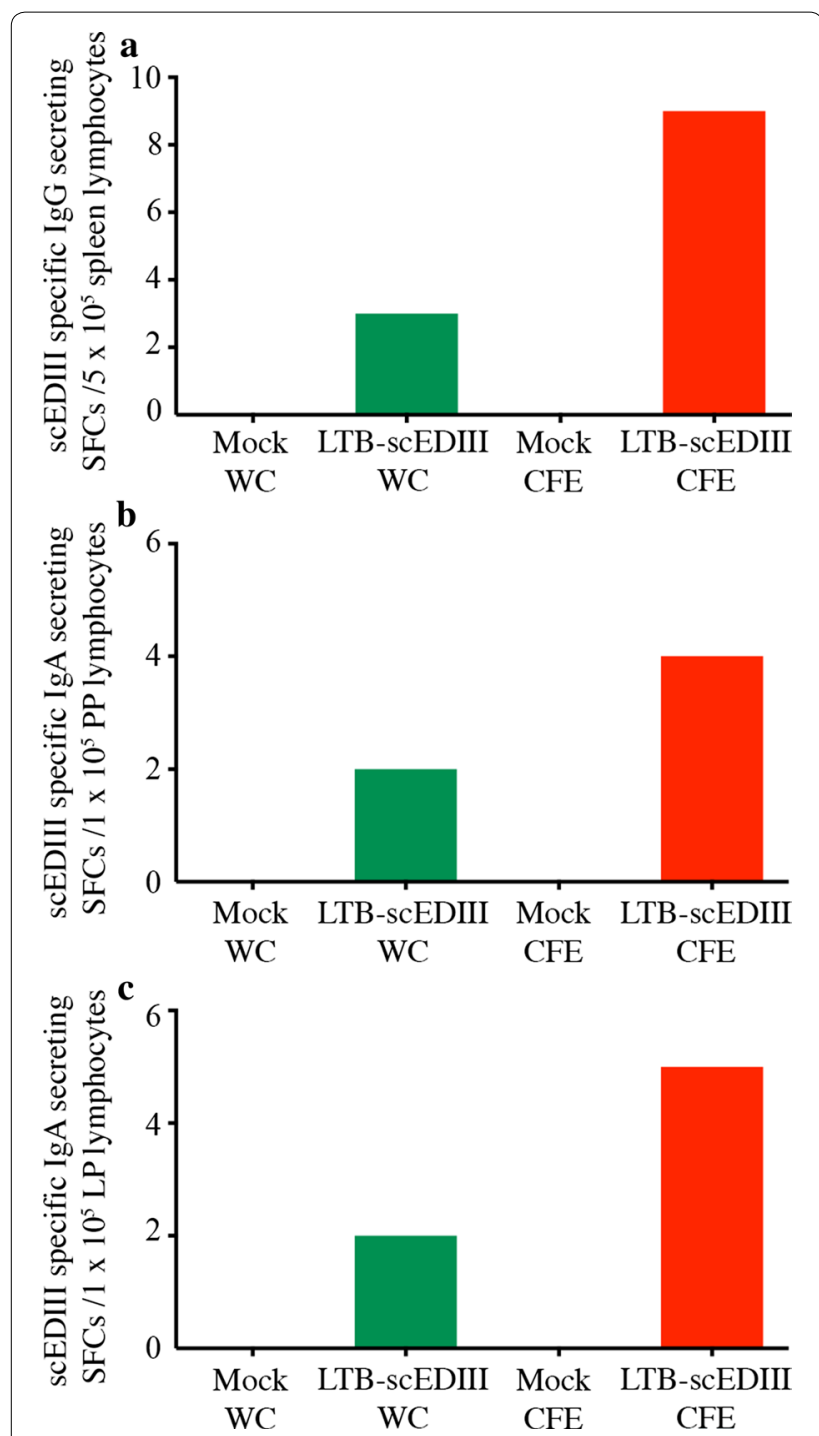

Fig. 5 Frequency of antigen-specific immune cells in orally immunized mice. ELISPOT assay showing scEDIII-specific IgG and IgA antibody spot forming cells in the lymphocytes isolated from spleens, $L P$, and PP of immunized mice. Each group represents two mice analyzed individually in triplicates. This is a representative result of two independent experiments showing similar results

$\mathrm{FNT}_{50}$ titers $>16$. LTB-scEDIII WC-derived antibody showed DENV1 $\mathrm{FNT}_{50}$ titers $>18$; however, significantly lower titers were observed with DENV2 $\left(\mathrm{FNT}_{50}>7\right)$, which suggests the inability of WC formulation in neutralizing DENV2.

\section{Oral immunization elicits memory response upon booster immunization}

An important feature of a vaccine is its ability to induce a long-term memory response to antigenic challenge. To determine whether memory immune cells had been

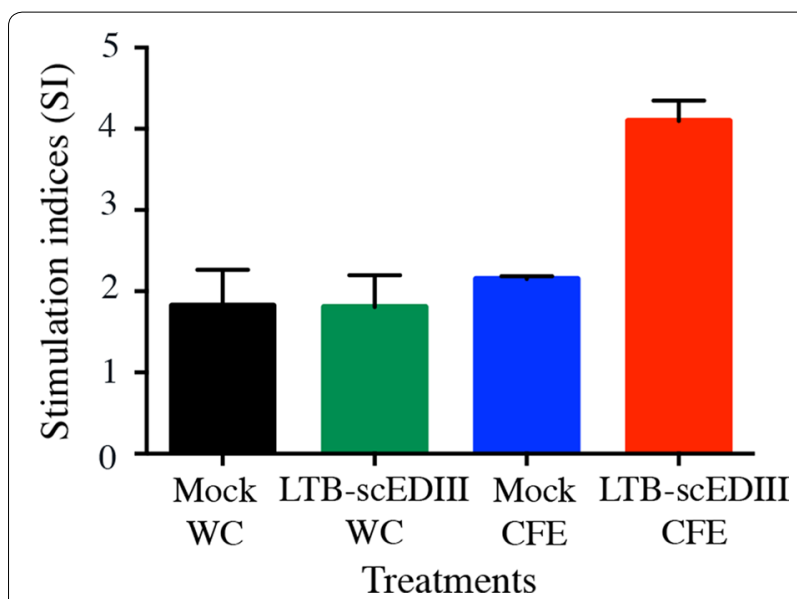

Fig. 6 Cellular immune responses upon oral immunization. Cellular immune responses represented by lymphocyte proliferation was determined from $\left[{ }^{3} \mathrm{H}\right]$-TdR incorporation after in vitro stimulation of isolated lymphocytes with E. coli expressed scEDIII, and results are expressed as stimulation indices. All assays were performed in triplicates and the values (from a representative experiment of typically three performed) are shown as the mean \pm standard deviation

established as a result of oral immunization, we evaluated serum IgG levels after an intra-peritoneal booster injection of $20 \mu \mathrm{g}$ of alum-adsorbed purified E. coliexpressed scEDIII was administered to each immunized mouse on day 43 following the last oral immunization. Retro-orbital bleedings were conducted after 3 days to collect serum for IgG analysis. Interestingly, although the immune response due to recombinant WC was considerably lower than that induced by recombinant CFE, the secondary immune response of recombinant WC surged and matched that of recombinant CFE upon intraperitoneal antigenic booster dose (Fig. 8). The IgG titers in both LTB-scEDIII CFE and LTB-scEDIII WC were significantly higher than those of the booster dose immunized Mock CFE and Mock WC, respectively. These results predict that a strong memory response might have been elicited upon oral immunization with LTB-scEDIII regardless of the $\mathrm{WC}$ and CFE preparation.

\section{Discussion}

In this study, we evaluated the efficacy of a dengue oral vaccine candidate administered to mice using WC and CFE preparations. We previously confirmed that yeast-expressed scEDIII resulted in a balanced immune response against all four serotypes [16], suggesting its role as a promising tetravalent dengue vaccine candidate. Furthermore, since LTB displays advantageous adjuvant properties as a co-administered or conjugated antigen $[40,41]$, we investigated the immunogenicity and 


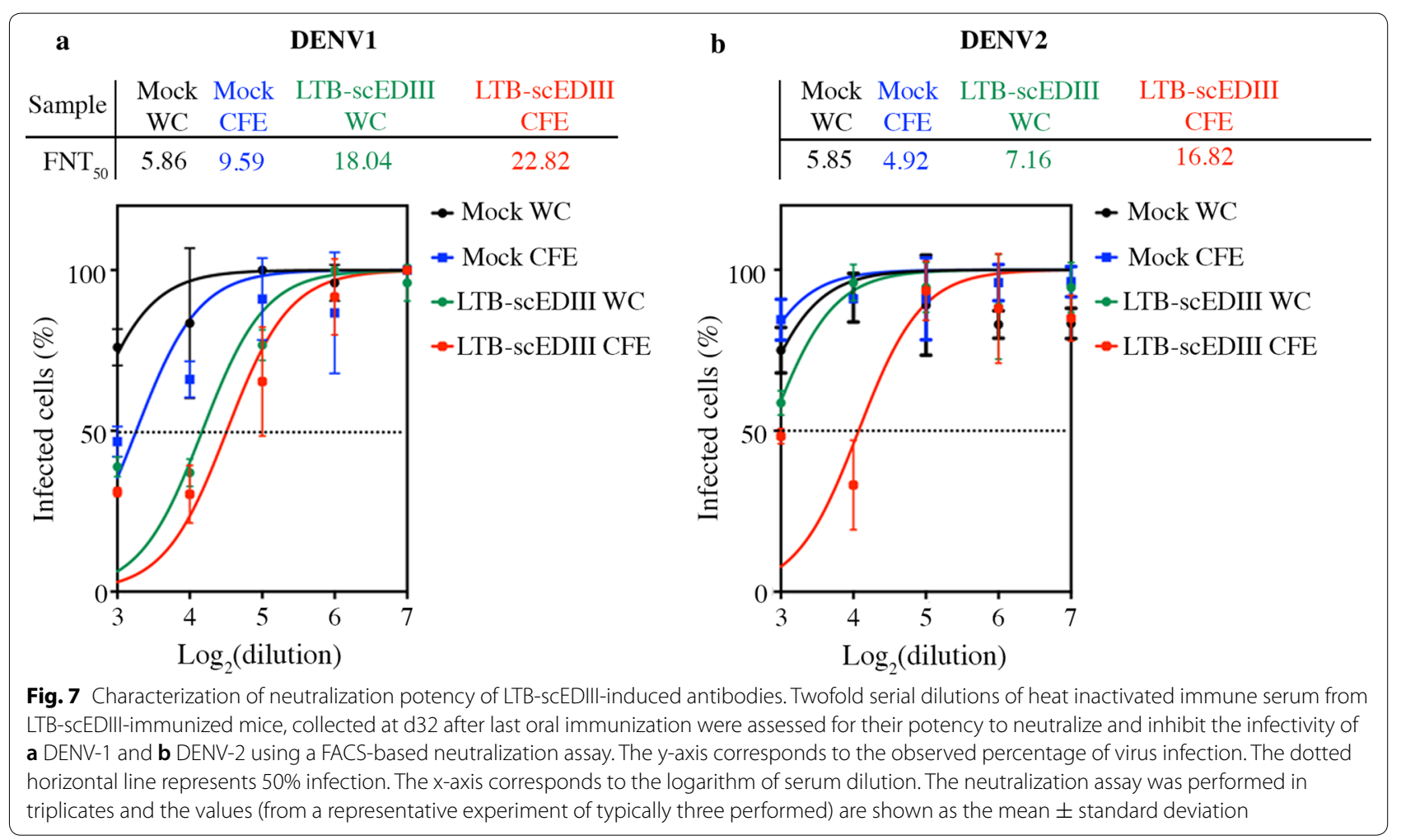

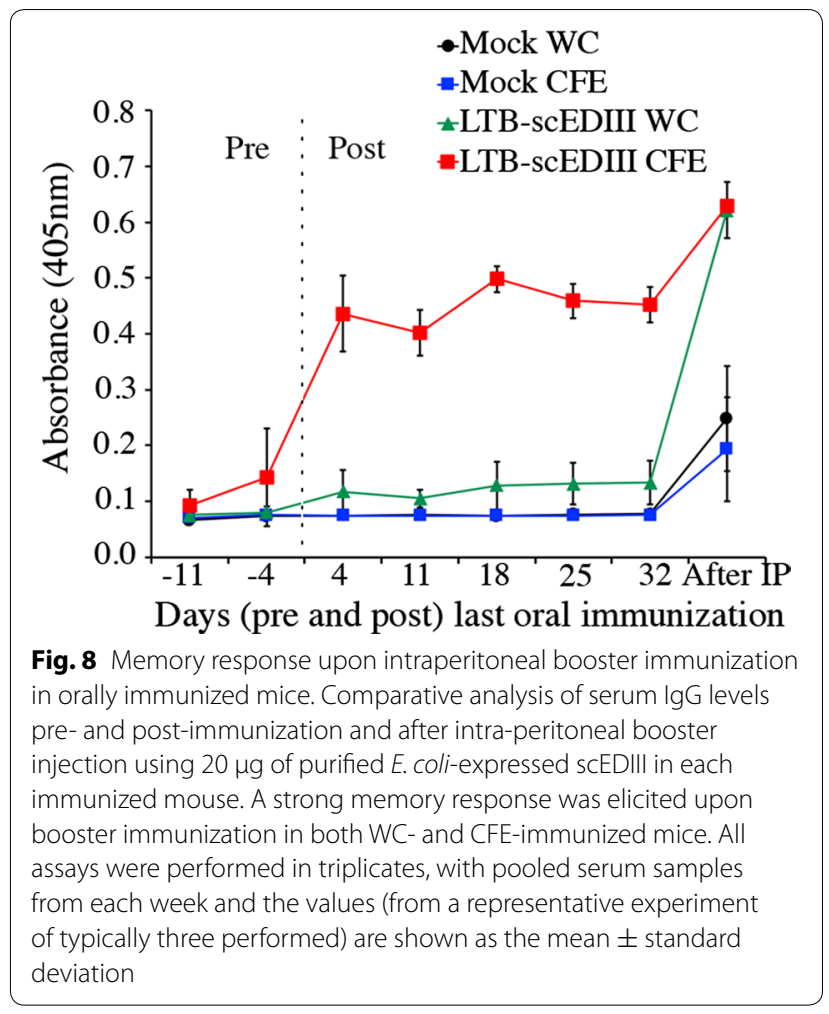

neutralization capacity of the oral vaccine consisting of yeast cells expressing the LTB-scEDIII fusion protein.

Before utilizing the $S$. cerevisiae-expressed LTB-scEDIII as an oral vaccine candidate, we determined whether the antigenic integrity of scEDIII was maintained, despite being fused to LTB. As expected, the recombinant protein preserved its antigenic identity, as it was detected by western blotting and indirect ELISA probed with antidengue $\mathrm{mAb}$. These results were consistent with previous findings, which showed that the dengue scEDIII fusion protein was expressed successfully in plant and yeast systems, preserving its antigenic properties [31, 42, 43]. The functionality of LTB as a potent immunoadjuvant depends on the pentameric formation of LTB, which is required for binding with GM1 ganglioside. Using a GM1 ELISA, we found that the LTB-scEDIII recombinant protein retained its biological ability to form pentameric associations. Previous studies reported that bacterial LTB subunits assembled into functional pentameric proteins in plants and yeast [44-46]. However, steric hindrance from large molecules fused with LTB might prevent pentamer formation $[47,48]$, suggesting that smaller targets or co-expression would be required for pentamer formation [34]. In our study, as scEDIII is a smaller protein, no 
such obstacles were observed. The yeast-expressed LTBscEDIII followed a similar pattern of GM1 binding as that of the positive control yeast expressing LTB, further proving its functional effectiveness.

After confirming the functional characteristics of the recombinant LTB-scEDIII protein, we investigated its immunogenicity. We found that all groups that received the recombinant protein using WC and CFE preparations developed anti-dengue IgG titers at 4 days after the last immunization, showing titers that differed significantly from controls. Similar observations were reported in a study using plant-based dengue oral immunization with CTB-sEDIII [49]. Mucosal vaccines given via the oral route can induce mucosal immunity, such as antigen-specific sIgA production, as well as systemic immunity [50]. In addition to systemic immunity, mucosal immunity was also elevated. Elevated fecal sIgA levels in both recombinant yeast WC- and CFE-fed mice apparently reflected enhanced stimulation by exposure of PP and LP to the same antigen LTB-scEDIII. Although the sIgA titers were low, upon further analysis, the numbers of AFCs in the lymphocytes isolated from spleen, LP, and PP were found to differ considerably between LTB-scEDIII-administered mice and their Mock-administered counterparts, irrespective of dosage preparation. Cellular immune responses are simultaneously essential in imparting protection against DENV infection. Although, the lack of DENV non-structural (NS) proteins, a source of T cell epitopes, in our scEDIII construct questions the ability to elicit $\mathrm{T}$ cell immune response that affects long-term immunogenicity and protection, previous studies have demonstrated the successful activation of $\mathrm{T}$ cells using DENV EDIII as a target. T cells from SPLs of EDIII-Co1A immunized mice successfully secreted cytokines such as IL-2, IL-4, IL-6 and IL-17 after in vitro EDIII stimulation [51]. The consensus EDIII expressed in both tobacco plants was reported to have induced a significant cellular immune response, in the form of IFNY production and polyfunctional $\mathrm{T}$ cells in both the CD4+ and CD8+ compartments [52]. In this study also, cellular immune response in the form of lymphocyte proliferative activity was elevated in CFE-fed mice. The overall limited efficacy of oral vaccines is both due to problems linked to antigen breakdown in the harsh gastric environment and also to the highly tolerogenic gut environment. The relative elicitation of an immune response confirmed the suppression of oral tolerance, a property that most LTB- and CTB-fused antigens reveal when administered without priming $[53,54]$.

Next, we evaluated the potential of the yeast derived LTB-scEDIII as an oral vaccine using WC and CFE preparations. Vaccines delivered orally are processed and presented in the mucosal system, thus targeted immunization requires efficient adjuvants. The CTB subunit from
Vibrio cholerae and the LTB subunit of E. coli are wellcharacterized mucosal carrier proteins [34, 48]. Saccharomyces cerevisiae is considered to be GRAS and is used as a food and feed ingredient $[55,56]$. It is suitably taken up by APCs $[25,26]$, and the immunostimulatory effects of the cell wall components have been reported in several yeast strains [57-59]. In the current study, the LTB-scEDIII antigen was expressed in S. cerevisiae, it folded efficiently into the biologically active pentameric form that interacted with GM1-ganglioside, and it was recognized by anti-LTB IgG. Oral immunization with WC or CFE preparations elicited potent humoral immune responses systemically and in the mucosa, as confirmed by the significantly high serum IgG and fecal sIgA levels in serum and fecal extracts, respectively, further justifying its use as an oral vaccine candidate.

Establishment of a memory response is an important criterion in designing and implementing an effective vaccine. Our studies revealed that feeding recombinant LTB-scEDIII WC or CFE to mice stimulated a primary immune response. Moreover, several weeks after the decline of specific antibodies to background levels, a single intra-peritoneal injection of purified scEDIII provoked a rapid surge in an immune response, especially in the WC-fed mice. The responses to the antigenic boost were significantly lower in mice that were fed with WC and CFE derived from Mock-transformed cells, showing that the boosting response elicited in mice fed with recombinant LTB-scEDIII WC or CFE was indeed the result of priming and establishment of immune memory to LTB-scEDIII presented in the gut. Although, further analysis through ELISPOT assay could not confirm the elevated immune response against LTB-scEDIII WC formulation, but LTB-scEDIII CFE immunized mice indicated significantly increased immune response ( $>$ fourfold rise) upon booster immunization. The level of the immune response to a booster immunization gets significantly elevated indicating vaccines can still rely on a significant local immunity that may interfere with colonization of the gut by the vaccine strain for a long time after basic immunization [60]. These data further indicate that LTB-scEDIII, produced and delivered via CFE dosage preparations, is an effective oral immunogen, representing a potent dengue oral vaccine candidate.

The ideal dengue vaccine should be free of significant reactogenicity, induce a life-long balanced and lasting immunity against all four DENV serotypes, and be affordable. Therefore, it should be capable of neutralizing DENV serotypes in a cost-effective manner. DENV EDIII is involved in receptor binding. It is the target of specific neutralizing antibodies, and is considered to be a promising subunit dengue vaccine candidate [61]. Our study using the FACS-based neutralization assay revealed that 
the antibodies produced against scEDIII through oral immunization can neutralize DENV1 and DENV2 serotypes, the representative serotypes causing severe dengue infection. Earlier reports indicated that DENV1 and DENV2 were the predominant serotypes in a case study in Singapore [62]. Studies in Thailand and Taiwan found a significant correlation between DENV-2 and greater disease severity [63]. DENV2 induced increased disease severity, which was correlated with high viremia titer and secondary dengue infection [64]. In our study, the neutralization titers were higher in CFE-fed mice compared with WC-fed mice.

Antigen delivery by oral route is thought to be an ideal strategy for vaccination. Oral vaccines are particularly attractive for immunization in developing countries as they enable mass vaccination at relatively low cost, help avoid the risks commonly associated with conventional vaccines, and confer enhanced immune responses at mucosal sites and systemically $[65,66]$. Dengue is listed as a neglected tropical disease, and apart from the technical constraints, the costs associated with mass immunization, maintenance of a sustained supply, and potential safety issues are major concerns in its eradication $[6,67]$. The current study presents a cost-effective oral vaccination strategy for administering S. cerevisiae-expressed LTB-scEDIII in the form of WC or CFE. This strategy does not require intricate processing, it elicits humoral and cell-mediated immune responses, and stimulates neutralizing antibodies against dengue virus serotypes.

Although both dosage forms of the evaluated dengue vaccine strategy elicited humoral and cellular immune response with high neutralizing efficiency and strong memory responses, immunization with WC elicited a lowered immune response and neutralization efficiency in comparison with CFE. This lower response may be caused by improper targeting. The yeast cell surface is a functional interface where natively displayed molecules on the surface play important roles in various biological or physiological processes [68]. Thus, the strategy of displaying target proteins on the yeast surface is currently used as an efficient vaccine delivery system [69, 70]. Therefore, the elicited immune response due to oral administration of LTB-scEDIII WC could be improved through the surface display of scEDIII, thus enhancing mucosal targeting of the target antigen. Future studies should investigate the advantages of displaying antigen on the yeast surface in the development of efficient oral dengue vaccines.

\section{Conclusions}

This study is the first to report the potential of S. cerevisiae-expressed LTB-scEDIII as an oral vaccine candidate in the form of WC or CFE. Comparing the immunogenicity of WC and CFE vaccine delivery, oral immunization with CFE provoked higher humoral and cellular immune responses as well as higher neutralizing titers. However, WC-immunized mice showed a stronger memory response upon intraperitoneal booster dose. These findings suggest that the LTB-scEDIII fusion protein delivered in the form of CFE rather than WC shows promise as a potent oral vaccine candidate against dengue virus infection.

\section{Additional file}

Additional file 1. Comparative immunogenicity of preparations of yeastderived dengue oral vaccine candidate.

\section{Abbreviations}

DENV: dengue virus; WC: whole recombinant yeast cells; CFE: cell-free extracts; LTB: heat-labile toxin protein B-subunit; scEDIII: consensus dengue envelope domain III; DHF: dengue hemorrhagic fever; CFA: complete Freund's adjuvant; APCs: antigen presenting cells; MHC: major histocompatibility complex; GRAS: generally regarded as safe; PP: Peyer's patches; LP: lamina propria; PCV2b: porcine circovirus type 2; ura- : uracil-deficient; SDS-PAGE: SDS-polyacrylamide gel electrophoresis; TSP: total soluble protein; ELISA: enzyme linked immunosorbent assay; SI: stimulation indices; ELISPOT: enzyme-linked immunosorbent spot.

\section{Authors' contributions}

$\mathrm{DK}, J \mathrm{~B}, \mathrm{NL}, \mathrm{JP}$ and $\mathrm{YJ}$ contributed to the conception or design of the work. JB and NL performed cloning, expression and antigen preparation. JB performed immunization work and ELISA. JB and JP performed ELISPOT and JP helped with FNT assay. JB contributed towards data acquisition and analysis and wrote the original manuscript. All authors provided inputs for the initial draft and approved the final version. DK, KDS and YSJ contributed towards critical reviewing and editing of the manuscript. All authors read and approved the final manuscript.

\section{Author details}

${ }^{1}$ Department of Molecular Biology, Department of Bioactive Material Sciences, Institute for Molecular Biology and Genetics, Chonbuk National University, Jeonju, Jeollabuk-do 54896, Republic of Korea. ${ }^{2}$ Department of Biology, College of Sciences, Hue University, Hue, Vietnam. ${ }^{3}$ Department of Animal Biotechnology, The Animal Molecular Genetics and Breeding Center, Chonbuk National University, Jeonju, Jeollabuk-do 54896, Republic of Korea.

\section{Acknowledgements}

The authors are grateful to Dr. Truong (National institute of Hygiene and Epidemiology of Vietnam, Hanoi, Vietnam) for providing the DENVs used in this study. We are thankful to the Institute of Molecular Biology and Genetics at Chonbuk National University for kindly providing the facilities for this research.

\section{Competing interests}

The authors declare that they have no competing interests.

\section{Availability of data and materials}

All data generated or analyzed during this study are included in this published article (and its Additional files).

\section{Consent for publication}

Not relevant.

\section{Ethics approval and consent to participate}

Experimental procedures involving laboratory animals strictly adhered to the guidelines set out by the Institutional Animal Care and Use Committee of the Chonbuk National University (Approval Number: CBU 2015-0004). 


\section{Funding}

This work was supported in part by the Basic Science Research Program through the National Research Foundation of Korea (NRF) funded by the Ministry of Education (2017R1A6A1A03015876), the NRF Grant by MSIP (2015R1A2A1A10055684) and a Grant from the Next-Generation BioGreen 21 Program (No. PJ01104401), Rural Development Administration, Republic of Korea.

\section{Publisher's Note}

Springer Nature remains neutral with regard to jurisdictional claims in published maps and institutional affiliations.

Received: 24 November 2017 Accepted: 9 February 2018

Published online: 16 February 2018

\section{References}

1. WHO. Dengue: guidelines for diagnosis, treatment, prevention, and control. Special Programme for Research, Training in Tropical Diseases. 2009; 409:147. WHO/HTM/NTD/DEN/2009.1.

2. Bhatt $S$, Gething PW, Brady OJ, Messina JP, Farlow AW, Moyes $C L$, Drake JM, Brownstein JS, Hoen AG, Sankoh O, et al. The global distribution and burden of dengue. Nature. 2013;496:504-7.

3. Hadinegoro SR, Arredondo-Garcia JL, Capeding MR, Deseda C, Chotpitayasunondh T, Dietze R, Muhammad Ismail HI, Reynales H, Limkittiku K, Rivera-Medina DM, et al. Efficacy and long-term safety of a dengue vaccine in regions of endemic disease. N Engl J Med. 2015;373:1195-206.

4. Katzelnick LC, Fonville JM, Gromowski GD, Bustos Arriaga J, Green A James SL, Lau L, Montoya M, Wang C, VanBlargan LA, et al. Dengue viruses cluster antigenically but not as discrete serotypes. Science. 2015;349:1338-43.

5. Halstead SB. Neutralization and antibody-dependent enhancement of dengue viruses. Adv Virus Res. 2003;60:421-67.

6. Murphy BR, Whitehead SS. Immune response to dengue virus and prospects for a vaccine. Annu Rev Immunol. 2011;29:587-619.

7. Gubler DJ, Kuno G, Markoff L. Flaviviruses. In: Knipe DM, Howley PM, editors. Fields virology. 5th ed. Philadelphia: Wolters Kluwer and Lippincott Williams \& Wilkins; 2007. p. 1153-252.

8. Swaminathan S, Khanna N. Dengue: recent advances in biology and current status of translational research. Curr Mol Med. 2009;9:152-73.

9. Chen Y, Maguire T, Hileman RE, Fromm JR, Esko JD, Linhardt RJ, Marks RM. Dengue virus infectivity depends on envelope protein binding to target cell heparan sulfate. Nat Med. 1997;3:866-71.

10. Chen YC, Wang SY, King CC. Bacterial lipopolysaccharide inhibits dengue virus infection of primary human monocytes/macrophages by blockade of virus entry via a CD14-dependent mechanism. J Virol. 1999;73:2650-7.

11. Gromowski GD, Barrett AD. Characterization of an antigenic site that contains a dominant, type-specific neutralization determinant on the envelope protein domain III (ED3) of dengue 2 virus. Virology. 2007:366:349-60

12. Guzman MG, Hermida L, Bernardo L, Ramirez R, Guillen G. Domain III of the envelope protein as a dengue vaccine target. Expert Rev Vaccines. 2010;9:137-47.

13. Whitehead SS, Blaney JE, Durbin AP, Murphy BR. Prospects for a dengue virus vaccine. Nat Rev Microbiol. 2007;5:518-28.

14. Leng CH, Liu SJ, Tsai JP, Li YS, Chen MY, Liu HH, Lien SP, Yueh A, Hsiao $\mathrm{KN}$, Lai LW, et al. A novel dengue vaccine candidate that induces cross-neutralizing antibodies and memory immunity. Microbes Infect. 2009;11:288-95

15. Chiang CY, Liu SJ, Tsai JP, Li YS, Chen MY, Liu HH, Chong P, Leng CH, Chen HW. A novel single-dose dengue subunit vaccine induces memory immune responses. PLoS ONE. 2011;6:e23319.

16. Nguyen NL. Development of recombinant dengue vaccines using Saccharomyces cerevisiae and cloning and characterization of fungal polyketide synthase genes in the pathogenic fungus Cladosporium phlei. Jeonju: Chonbuk National University, Department of Molecular Biology; 2013.
17. Bucarey SA, Noriega J, Reyes P, Tapia C, Saenz L, Zuniga A, Tobar JA. The optimized capsid gene of porcine circovirus type 2 expressed in yeast forms virus-like particles and elicits antibody responses in mice fed with recombinant yeast extracts. Vaccine. 2009;27:5781-90.

18. Nguyen NL, So KK, Kim JM, Kim SH, Jang YS, Yang MS, Kim DH. Expression and characterization of an $\mathrm{M}$ cell-specific ligand-fused dengue virus tetravalent epitope using Saccharomyces cerevisiae. J Biosci Bioeng. 2015;119:19-27.

19. Areas AP, Oliveira ML, Miyaji EN, Leite LC, Aires KA, Dias WO, Ho PL. Expression and characterization of cholera toxin B-pneumococcal surface adhesin A fusion protein in Escherichia coli: ability of CTB-PsaA to induce humoral immune response in mice. Biochem Biophys Res Commun. 2004;321:192-6.

20. Arakawa T, Yu J, Chong DK, Hough J, Engen PC, Langridge WH. A plantbased cholera toxin B subunit-insulin fusion protein protects against the development of autoimmune diabetes. Nat Biotechnol. 1998;16:934-8.

21. Sadeghi H, Bregenholt S, Wegmann D, Petersen JS, Holmgren J, Lebens M. Genetic fusion of human insulin B-chain to the B-subunit of cholera toxin enhances in vitro antigen presentation and induction of bystander suppression in vivo. Immunology. 2002;106:237-45.

22. Nashar TO, Betteridge ZE, Mitchell RN. Evidence for a role of ganglioside GM1 in antigen presentation: binding enhances presentation of Escherichia coli enterotoxin B subunit (EtxB) to CD4(+) T cells. Int Immunol. 2001;13:541-51.

23. De Haan L, Hearn AR, Rivett AJ, Hirst TR. Enhanced delivery of exogenous peptides into the class I antigen processing and presentation pathway. Infect Immun. 2002;70:3249-58.

24. Nashar TO, Williams NA, Hirst TR. Cross-linking of cell surface ganglioside GM1 induces the selective apoptosis of mature CD8+ T lymphocytes. Int Immunol. 1996;8:731-6.

25. Thomas DS. Electropositively charged filters for the recovery of yeasts and bacteria from beverages. J Appl Bacteriol. 1988;65:35-41.

26. Xiang SD, Scholzen A, Minigo G, David C, Apostolopoulos V, Mottram PL, Plebanski M. Pathogen recognition and development of particulate vaccines: does size matter? Methods. 2006:40:1-9.

27. Stubbs AC, Martin KS, Coeshott C, Skaates SV, Kuritzkes DR, Bellgrau D, Franzusoff A, Duke RC, Wilson CC. Whole recombinant yeast vaccine activates dendritic cells and elicits protective cell-mediated immunity. Nat Med. 2001;7:625-9.

28. Kim HJ, Lee JY, Kang HA, Lee Y, Park EJ, Kim HJ. Oral immunization with whole yeast producing viral capsid antigen provokes a stronger humoral immune response than purified viral capsid antigen. Lett Appl Microbiol. 2014;58:285-91.

29. Blanquet S, Antonelli R, Laforet L, Denis S, Marol-Bonnin S, Alric M. Living recombinant Saccharomyces cerevisiae secreting proteins or peptides as a new drug delivery system in the gut. J Biotechnol. 2004;110:37-49.

30. Patterson R, Eley T, Browne C, Martineau HM, Werling D. Oral application of freeze-dried yeast particles expressing the PCV2b Cap protein on their surface induce protection to subsequent PCV2b challenge in vivo. Vaccine. 2015;33:6199-205

31. Lim JG, Kim JA, Chung HJ, Kim TG, Kim JM, Lee KR, Park SM, Yang MS, Kim $\mathrm{DH}$. Expression of functional pentameric heat-labile enterotoxin B subunit of Escherichia coli in Saccharomyces cerevisiae. J Microbiol Biotechnol. 2009;19:502-10.

32. Shin YM, Kwon TH, Kim KS, Chae KS, Kim DH, Kim JH, Yang MS. Enhanced iron uptake of Saccharomyces cerevisiae by heterologous expression of a tadpole ferritin gene. Appl Environ Microb. 2001;67:1280-3.

33. Gietz D, St Jean A, Woods RA, Schiestl RH. Improved method for high efficiency transformation of intact yeast cells. Nucleic Acids Res. 1992;20:1425.

34. Kim JM, Jung DI, Eom YJ, Park SM, Yoo HS, Jang YS, Yang MS, Kim DH. Surface-displayed expression of a neutralizing epitope of ApxllA exotoxin in Saccharomyces cerevisiae and oral administration of it for protective immune responses against challenge by Actinobacillus pleuropneumoniae. Biosci Biotechnol Biochem. 2010;74:1362-7.

35. Nguyen NL, Kim JM, Park JA, Park SM, Jang YS, Yang MS, Kim DH. Expression and purification of an immunogenic dengue virus epitope using a synthetic consensus sequence of envelope domain III and Saccharomyces cerevisiae. Protein Expr Purif. 2013;88:235-42.

36. Park J, Seo KW, Kim SH, Lee HY, Kim B, Lim CW, Kim JH, Yoo HS, Jang YS. Nasal immunization with $M$ cell-targeting ligand-conjugated ApxllA toxin 
fragment induces protective immunity against Actinobacillus pleuropneumoniae infection in a murine model. Vet Microbiol. 2015;177:142-53.

37. Kim SH, Seo KW, Kim J, Lee KY, Jang YS. The M cell-targeting ligand promotes antigen delivery and induces antigen-specific immune responses in mucosal vaccination. J Immunol. 2010;185:5787-95.

38. Kim SH, Jung DI, Yang IY, Kim J, Lee KY, Nochi T, Kiyono H, Jang YS. M cells expressing the complement $\mathrm{C} 5$ a receptor are efficient targets for mucosal vaccine delivery. Eur J Immunol. 2011;41:3219-29.

39. Kraus AA, Messer W, Haymore LB, de Silva AM. Comparison of plaqueand flow cytometry-based methods for measuring dengue virus neutralization. J Clin Microbiol. 2007;45:3777-80.

40. Chia MY, Hsiao SH, Chan HT, Do YY, Huang PL, Chang HW, Tsai YC, Lin $C M$, Pang VF, Jeng CR. Evaluation of the immunogenicity of a transgenic tobacco plant expressing the recombinant fusion protein of GP5 of porcine reproductive and respiratory syndrome virus and B subunit of Escherichia coli heat-labile enterotoxin in pigs. Vet Immunol Immunopathol. 2011;140:215-25.

41. Lakshmi PS, Verma D, Yang X, Lloyd B, Daniell H. Low cost tuberculosis vaccine antigens in capsules: expression in chloroplasts, bio-encapsulation, stability and functional evaluation in vitro. PLoS ONE. 2013;8:e54708.

42. Kim TG, Kim MY, Huy NX, Kim SH, Yang MS. M cell-targeting ligand and consensus dengue virus envelope protein domain III fusion protein production in transgenic rice calli. Mol Biotechnol. 2013;54:880-7.

43. Kim HA, Kwon SY, Yang MS, Choi PS. Expression of Dengue virus Elll domain-coding gene in maize as an edible vaccine candidate. J Plant Biotechnol. 2014;41:50.

44. Dertzbaugh MT, Elson CO. Comparative effectiveness of the cholera toxin B subunit and alkaline phosphatase as carriers for oral vaccines. Infect Immun. 1993;61:48-55.

45. Daniell H, Lee SB, Panchal T, Wiebe PO. Expression of the native cholera toxin $\mathrm{B}$ subunit gene and assembly as functional oligomers in transgenic tobacco chloroplasts. J Mol Biol. 2001;311:1001-9.

46. Julia Scerbo M, Bibolini MJ, Barra JL, Roth GA, Monferran CG. Expression of a bioactive fusion protein of Escherichia coli heat-labile toxin B subunit to a synapsin peptide. Protein Expr Purif. 2008;59:320-6.

47. Clements JD. Construction of a nontoxic fusion peptide for immunization against Escherichia coli strains that produce heat-labile and heat-stable enterotoxins. Infect Immun. 1990;58:1159-66.

48. Lee G, Jeong Y, Wirguin I, Hays AP, Willison HJ, Latov N. Induction of human IgM and IgG anti-GM1 antibodies in transgenic mice in response to lipopolysaccharides from Campylobacter jejuni. J Neuroimmunol. 2004:146:63-75.

49. Kim MY, Li JY, Tien NQ, Yang MS. Expression and assembly of cholera toxin B subunit and domain III of dengue virus 2 envelope fusion protein in transgenic potatoes. Protein Expr Purif. 2017;139:57-62.

50. Pavot V, Rochereau N, Genin C, Verrier B, Paul S. New insights in mucosal vaccine development. Vaccine. 2012;30:142-54.

51. Kim SH, Jung DI, Yang IY, Jang SH, Kim J, Truong TT, Pham TV, Truong NU, Lee KY, Jang YS. Application of an M-cell-targeting ligand for oral vaccination induces efficient systemic and mucosal immune responses against a viral antigen. Int Immunol. 2013;25:623-32.

52. Kim MY, Van Dolleweerd C, Copland A, Paul MJ, Hofmann S, Webster GR, Julik E, Ceballos-Olvera I, Reyes-Del Valle J, Yang MS, et al. Molecular engineering and plant expression of an immunoglobulin heavy chain scaffold for delivery of a dengue vaccine candidate. Plant Biotechnol J. 2017;15(12):1590-601.

53. Ruhlman T, Ahangari R, Devine A, Samsam M, Daniell H. Expression of cholera toxin B-proinsulin fusion protein in lettuce and tobacco chloroplasts - oral administration protects against development of insulitis in non-obese diabetic mice. Plant Biotechnol J. 2007:5:495-510.

54. Wang HB, Fang G, Yu WZ, Du F, Fan CX, Liu QL, Hao LX, Liu Y, Zheng JS, Qin ZY, et al. An outbreak of type pi vaccine-derived poliovirus in Sichuan province, China: emergence and circulation in an under-immunized population. PLoS ONE. 2014;9:e113880.

55. Salnur S, Gultepe N, Hossu B. Replacement of fish meal by yeast (Saccharomyces cerevisiae): effects on digestibility and blood parameters for gilthead sea bream (Sparus aurata). J Anim Vet Adv. 2009;8:2557-61.

56. Finnis CJ, Payne T, Hay J, Dodsworth N, Wilkinson D, Morton P, Saxton MJ, Tooth DJ, Evans RW, Goldenberg H, et al. High-level production of animalfree recombinant transferrin from Saccharomyces cerevisiae. Microb Cell Fact. 2010:9:87.
57. Cassone A, Marconi P, Bistoni F, Mattia E, Sbaraglia G, Garaci E, Bonmassar E. Immunoadjuvant effects of Candida albicans and its cell-wall fractions in a mouse lymphoma model. Cancer Immunol Immun. 1981;10:181-90.

58. Immunomodulators Poli G. In: Cancelotti FM, Galassi D, editors. Adjuvants, interferons and non-specific immunity. Brussels: Commission of the European Communities; 1984. p. 111-26.

59. Rorstad G, Aasjord PM, Robertsen B. Adjuvant effect of a yeast glucan in vaccines against furunculosis in Atlantic salmon (Salmo-Salar L.). Fish Shellfish Immunol. 1993:3:179-90.

60. Kantele A, Makela PH. Different profiles of the human immune response to primary and secondary immunization with an oral Salmonella typhi Ty21a vaccine. Vaccine. 1991;9:423-7.

61. Chen J, Wen $K$, Li XQ, Yi HS, Ding XX, Huang YF, Pan YX, Hu DM, Di B, Che XY, Fu N. Functional properties of DENV EDIII-reactive antibodies in human DENV-1-infected sera and rabbit antiserum to EDIII. Mol Med Rep. 2016;14:1799-808.

62. Yung CF, Lee KS, Thein TL, Tan LK, Gan VC, Wong JG, Lye DC, Ng LC, Leo YS Dengue serotype-specific differences in clinical manifestation, laboratory parameters and risk of severe disease in adults, Singapore. Am J Trop Med Hyg. 2015;92:999-1005.

63. Vaughn DW, Green S, Kalayanarooj S, Innis BL, Nimmannitya S, Suntayakorn S, Endy TP, Raengsakulrach B, Rothman AL, Ennis FA, Nisalak A. Dengue viremia titer, antibody response pattern, and virus serotype correlate with disease severity. J Infect Dis. 2000;181:2-9.

64. Vicente CR, Herbinger KH, Froschl G, Romano CM, Cabidelle ADSA, Junior CC. Serotype influences on dengue severity: a cross-sectional study on 485 confirmed dengue cases in Vitoria, Brazil. BMC Infect Dis. 2016;16:320.

65. Wang L, Coppel RL. Oral vaccine delivery: can it protect against nonmucosal pathogens? Expert Rev Vaccines. 2008;7:729-38.

66. Levine MM. Immunogenicity and efficacy of oral vaccines in developing countries: lessons from a live cholera vaccine. BMC Biol. 2010:8:129.

67. Kanesa-thasan N, Sun W, Kim-Ahn G, Van Albert S, Putnak JR, King A, Raengsakulsrach B, Christ-Schmidt H, Gilson K, Zahradnik JM, et al. Safety and immunogenicity of attenuated dengue virus vaccines (Aventis Pasteur) in human volunteers. Vaccine. 2001;19:3179-88.

68. Shibasaki S, Maema H, Ueda M. Molecular display technology using yeast-arming technology. Anal Sci. 2009;25:41-9.

69. Tanaka T, Yamada R, Ogino C, Kondo A. Recent developments in yeast cell surface display toward extended applications in biotechnology. Appl Microbiol Biotechnol. 2012;95:577-91.

70. Luo S, Yan L, Zhang X, Yuan L, Fang Q, Zhang YA, Dai H. Yeast surface display of capsid protein VP7 of grass carp reovirus: fundamental investigation for the development of vaccine against hemorrhagic disease. J Microbiol Biotechnol. 2015;25:2135-45.

\section{Submit your next manuscript to BioMed Central and we will help you at every step:}

- We accept pre-submission inquiries

- Our selector tool helps you to find the most relevant journal

- We provide round the clock customer support

- Convenient online submission

- Thorough peer review

- Inclusion in PubMed and all major indexing services

- Maximum visibility for your research

Submit your manuscript at www.biomedcentral.com/submit
(O) BioMed Central 